Lehmann, A.; Bach, V.; Finkbeiner, M.

\title{
Product environmental footprint in policy and market decisions: Applicability and impact assessment
}

Journal article | Accepted manuscript (Postprint)

This version is available at https://doi.org/10.14279/depositonce-8564

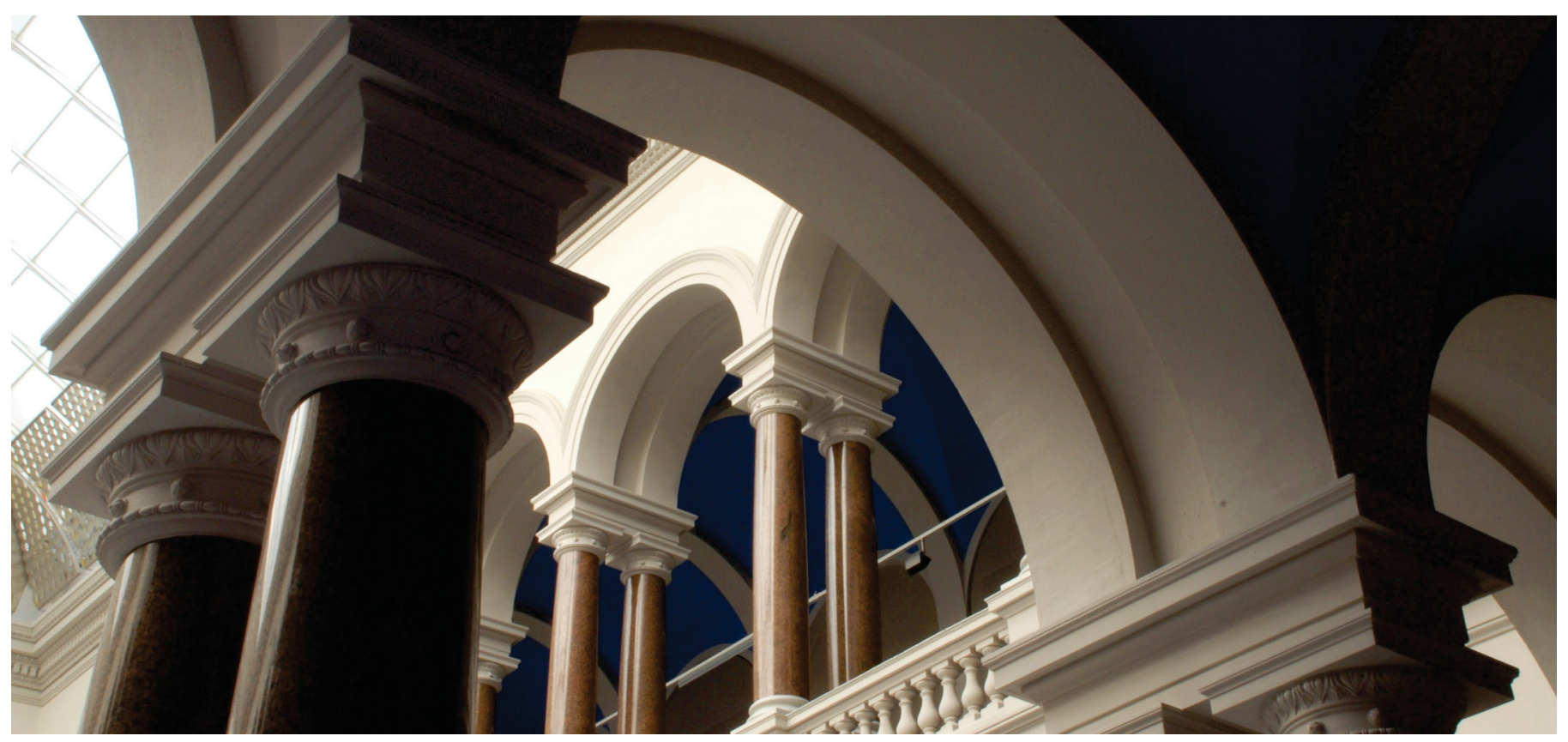

This is the peer reviewed version of the following article:

Lehmann, A., Bach, V., \& Finkbeiner, M. (2015). Product environmental footprint in policy and market decisions: Applicability and impact assessment. Integrated Environmental Assessment and Management, 11(3), 417-424. https://doi.org/10.1002/ieam.1658,

which has been published in final form at https://setac.onlinelibrary.wiley.com/doi/10.1002/ieam.1658. This article may be used for non-commercial purposes in accordance with Wiley Terms and Conditions for Use of Self-Archived Versions.

\section{Terms of Use}

Copyright applies. A non-exclusive, non-transferable and limited right to use is granted. This document is intended solely for 


\title{
Product Environmental Footprint in Policy and Market Decisions: Applicability and Impact Assessment
}

\author{
Annekatrin Lehmann ${ }^{1 *}$, Vanessa Bach $^{1 *}$ and Matthias Finkbeiner ${ }^{1}$ \\ ${ }^{1}$ Chair of Sustainable Engineering, Department of Environmental Technology, Technische Universität Berlin, Berlin, Germany \\ Lehmann and Bach contributed equally to the work. \\ * Address correspondence to: vanessa.bach@tu-berlin.de
}

\section{EDITOR'S NOTE:}

This paper represents 1 of 7 articles in the special series "LCA Case Study Symposium 2013," which was generated from the $19^{\text {th }}$ SETACLCA Case Study Symposium "LCA in market research and policy: Harmonization beyond standardization, "heldin November 2013, in Rome, Italy. This collection of invited papers reflect the purpose of the symposium and focus on how LCA can support the decisionmaking process at all levels, that is, industry and policy contexts, and how LCA results can be efficiently communicated and be used to support market strategies.

\section{ABSTRACT}

In April 2013, the European Commission published the Product and Organisation Environmental Footprint (PEF/OEF) methodology-a life cycle-based multicriteria measure of the environmental performance of products, services, and organizations. With its approach of "comparability over flexibility," the PEF/OEF methodology aims at harmonizing existing methods, while decreasing the flexibility provided by the International Organization for Standardization (ISO) standards regarding methodological choices. Currently, a 3-y pilot phase is running, aiming at testing the methodology and developing product category and organization sector rules (PEFCR/OEFSR). Although a harmonized method is in theory a good idea, the PEF/OEF methodology presents challenges, including a risk of confusion and limitations in applicability to practice. The paper discusses the main differences between the PEF and ISO methodologies and highlights challenges regarding PEF applicability, with a focus on impact assessment. Some methodological aspects of the PEF and PEFCR Guides are found to contradict the ISO 14044 (2006) and ISO 14025 (2006). Others, such as prohibition of inventory cutoffs, are impractical. The evaluation of the impact assessment methods proposed in the PEF/OEF Guide showed that the predefined methods for water consumption, land use, and abiotic resources are not adequate because of modeling artefacts, missing inventory data, or incomplete characterization factors. However, the methods for global warming and ozone depletion perform very well. The results of this study are relevant for the PEF (and OEF) pilot phase, which aims at testing the PEF (OEF) methodology (and potentially adapting it) as well as addressing challenges and coping with them.

Keywords: Comparability; Harmonization; Impact assessment; ISO 14044; ISO 14025; OEF; PEF 


\section{INTRODUCTION}

International Organization for Standardization (ISO) 14044 (2006) is currently the only standardized method to assess a range of potential environmental impacts of products and services. It is transparent, widely used, and accepted throughout policy and in the market. Life Cycle Assessment (LCA) is applied both internally for environmentally oriented product and process development as well as externally to document environmental performance in environmental product declarations or in the development of type I label criteria. In 2013, the European Commission published the Product and Organisation Environmental Footprint (PEF/OEF) methodology-a life cycle-based multicriteria measure of the environmental performance of products, services, and organizations (European Union 2013a) (PEF/OEFGuide), developed as part of the 2020 European strategy "A resource efficient Europe" (European Union 2013b). With its approach of "comparability over flexibility," the PEF/OEF methodology aims at harmonizing existing methods, while decreasing the flexibility provided by the ISO standards regarding methodological choices. This is reflected, for example, in predefined life cycle impact assessment (LCIA) methods.

The PEF/OEF methodology is currently widely discussed amongst stakeholders, and skepticism exists in industry and consumer organizations, as well as in the scientific community. For example, concerns expressed by the European Automobiles Manufacturers Association (ACEA), Orgalime (European Engineering Industries Association), and the European consumer voice in standardization (ANEC) (Orgalime, ACEA, ANEC 2013) refer to potential unfair competition and market distortion at the consumer level. Concerns from a scientific perspective are described in Finkbeiner (2014) including a lack of conformity with international standards, predefined and partly untested impact assessment methods, and objections to the PEF/OEF "comparability over flexibility" approach.

Therefore, the methodology is also a challenge for existing environmental labeling schemes such as The Blue Angel (https://www.blauer-engel.de/) or the EU-Flower (http://ec.europa.eu/environment/ ecolabel/index_en.htm). Altogether, this reveals risks of impeding a life cycle-based environmental analysis of products and services.

The first wave of a 3-y PEF/OEF pilot phase started in November 2013 with the aim of testing the methodology in practice and developing product category and organization sector rules (PEFCR/OEFSR) for selected products and sectors; a second wave started in June 2014. PEFCRs and OEFSRs are life cycle-based rules that complement the general PEF/OEF Guide by providing further specification at the level of a specific product or sector category (European Commission 2014a). In the pilot phase, challenges regarding its applicability-known as well as new ones, likely to appear during the pilot phase-need to be addressed and coped with.

The goal of this article is to present and discuss the main differences between the PEF and the ISO methodologies (ISO 14044 [2006] and ISO 14025 [ISO 14025 2006]), identify and highlight related challenges regarding the PEF methodology and its applicability in practice, with a focus laid on impact assessment. Our report complements the previous analyses in the PEF Guide (European Union 2013a, Annex X) and Finkbeiner (2014) by further discussing challenges and the applicability of the PEF requirements. Regarding the impact assessment, 14 methods on midpoint level that were adopted by the PEF/OEF methodology and have to be applied when carrying out a PEF/OEF study were evaluated. Even though an analysis of these methods exists, conducted within the ILCD (International Reference Life Cycle Data System) Handbook (European Commission-Joint Research Centre-Institute for Environment and Sustainability 2011) in a comprehensive way, important criteria regarding their applicability are underrepresented in that analysis and thus picked up in this paper. Hence, our evaluation complements the existing assessment and highlights challenges of the 
proposed impact assessment methods. Additionally, selected challenges of the PEF methodology identified in our analyses are illustrated by using a theoretical example.

\section{METHODOLOGICAL APPROACH}

This study followed a 2-step approach: 1) summary and discussion of differences between the ISO and the PEF and highlighting challenges of the methodology, and 2) a thorough analysis of the PEF/OEF impact assessment methods and description of their challenges. The methodological approach of the latter is further described in the next subsection. A theoretical example (comparing biobased with conventional plastics) was used to test selected methodological requirements of the PEF methodology and to illustrate the identified challenges. As an illustrative example, we compare a thermoplastic cellulose acetate and a thermoplastic polymethylmethacrylate for biobased and conventional plastics, respectively (with a functional unit of $1 \mathrm{~kg}$ plastic).

This example addresses all challenges related to the impact assessment and the following selected other challenges: identification of a suitable CPA/NACE code (Classification of Products by Activity/Nomenclature statistique des activites economiques dans la Communaute europeenne) and the ban of cutoffs.

\section{Criteria-based evaluation of impact assessment methods}

To assess the suitability of the methods, a new evaluation scheme based on the evaluations from the European Commission Joint Research Centre (2011) and Reimann et al. (2010) was developed.

Overall, 4 main criteria are considered for evaluation: "stakeholder acceptance," "documentation and review," "environmental relevance," and "applicability." As shown in Figure 1, each criterion is specified by 2 to 5 subcriteria.

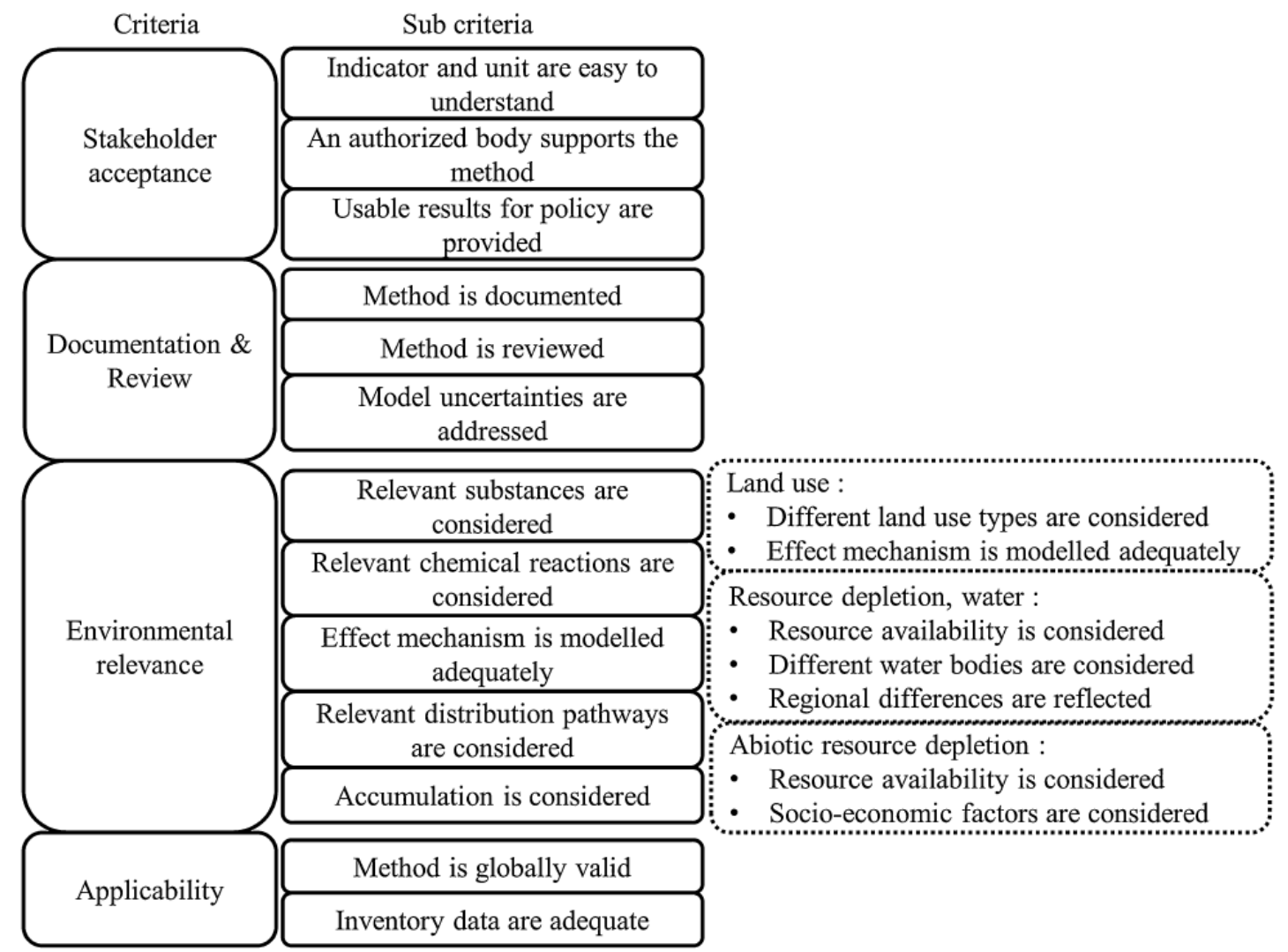

Figure 1. Assessment scheme for evaluating 14 impact assessment methods considering 4 main criteria each with 2-5 subcriteria. 
For the criterion "stakeholder acceptance," 3 subcriteria were considered. They were chosen to represent the following requirements: To communicate the results to the broad public or layperson, politics, and industry, the impact indicator as well as the corresponding unit has to be easy to understand. Moreover, when being supported by an authorized body, it is more likely that the method will be accepted by other stakeholders as well. For the criterion "usable results for policy are provided," all considered impact assessment categories are assumed to be relevant for politics or policy. Thus, the assessment focuses on whether the models are able to provide results that are useful on a policy level.

The criterion "documentation and review" has been evaluated based on whether the method is documented and reviewed and uncertainties are addressed. A thorough documentation of the method itself, background models, and resulting available characterization factors other than a reviewed journal paper is required for a holistic understanding. Furthermore, the scientific quality of the method is assumed to be higher when scientists dealing with the same or related topics have reviewed the method thoroughly. Addressing uncertainties regarding, for example, model assumptions - qualitatively as well as quantitatively (as done within the USEtox model [Rosenbaum et al. 2011])-improves the understanding of potential uncertainties of the impact assessment results, which therefore supports the interpretation.

The third criterion, "environmental relevance," evaluates the ability of a method to reflect the impacts on the environment adequately. Therefore, it is evaluated in the sub criteria if relevant substances and chemical reactions are considered, if effect mechanisms are modeled adequately, and if relevant distribution pathways and accumulation are considered. Furthermore, in a method properly reflecting the environmental impacts, characterization factors are assumed to be provided for all relevant substances. Missing factors would lead to a neglect of substances relevant for the impact category. Thus, as a first step, a classification of all relevant substances has to take place. Relevant substances can be identified based on the current knowledge in this field. Moreover, existing impact assessment methods should be included, because the elementary flows considered up to now are assumed to present relevant substances for this category. Based on the identified relevant substances, related chemical reactions and distribution pathways should be identified considering state-of-the-art research in the individual science disciplines. The work of the Intergovernmental Panel on Climate Change (IPCC 2007), for example, recently highlighted the growing problem of ocean acidification, which is so far not covered in LCA. Based on this research, an LCIA method can be developed considering relevant elementary flows such as carbon dioxide as well as relevant reactions such as the formation of hydrogen ions in water. Because the impact categories land use, depletion of water, and depletion of abiotic resources are input based, they have to be evaluated with a different set of criteria. For a comprehensive assessment of land use, the different land use types have to be considered, because their contribution to biodiversity or soil quality varies. Also, several effect mechanisms attributable to different land use types have to be modeled adequately. For water depletion, the resource availability and differentiation of water bodies need to be considered within the model, and regional aspects have to be reflected. To determine abiotic resource depletion, both the physical availability as well as socioeconomic aspects have to be considered.

The fourth criterion assesses the applicability of the impact assessment method. A sufficient amount of inventory data has to be available to use the method in practice. Global validity is also important, because supply chains have a global, not a European, scope.

As a result, the methods are ranked between levels 1 and 3 for each criterion. A 3-level approach was chosen for the classification, following an easy-to-understand traffic light rating system. Such systems are already widely applied in literature, for example, for impact assessment in Social LCA 
(e.g., Franze and Ciroth 2011; Martınez-Blanco et al. 2014). A classification of 1 indicates that the method fulfils all requirements of the criterion, and a ranking of 3 means that the demands could not be reached. Because many methods can only partly achieve the criteria requirements, an intermediate ranking was included (level 2).

The concluding recommendation is based on the results of this assessment and supported by an example comparing bio-based and conventional plastics.

\section{RESULTS AND DISCUSSION}

In the following sections, we summarize the differences between ISO and PEF methodologies and the identified challenges as well as the results from the evaluation of impact assessment methods, using the previously mentioned example for illustration.

\section{Differences between ISO and PEF and challenges of the PEF methodology}

The PEF differs regarding goal and scope, mainly because it introduces a set of new terminology for globally accepted terms (e.g., unit of analysis instead of functional unit), it is communication driven, whereas ISO is not, and it specifies how the unit of analysis shall be defined (amongst other methods, linked with CPA/NACE codes) (see also Finkbeiner [2014]). The introduction of (in our opinion unnecessary) new terms was already reviewed by the European Commission, noting that renaming common terms found limited support by the stakeholders (Galatola and Pant 2014). With regard to communication, appropriate methods or vehicles are yet missing. In the context of communication (and intended application), in the PEF overview on key requirements of PEF methodology (European Union 2013a, Annex X), business-to-business and business-to-consumers are claimed as communication targets of ISO 14044, whereas this is not directly stated in ISO 14044 (2006). The PEF requirement of linking the unit of analysis with CPA/NACE codes appears not to be a straightforward task: Taking the theoretical example on bio-based and conventional plastics, the category "manufacture of plastic products" (CPA/NACE code 25.2) would apply most. However, more than 1 category would be needed to cover the product system adequately-the production of raw materials for bio-based plastic (here mainly cellulose from recycled paper and pulpwood), for example, differs from raw material production of conventional plastic, but it is not reflected in the previously mentioned category and should thus be described in an additional category (maybe CPA/NACE code 17.12, "manufacture of paper and paperboard").

Regarding the inventory, one main difference is that the PEF Guide does not allow cutoffs. This would mean that all processes have to be modeled-in the plastics example, all machinery, even the extruder, which has a negligible contribution to the overall environmental impact. This is hardly feasible in practice, because it causes extra effort and costs without providing additional information. However, this requirement is relativized in the PEFCR Guide: although not using the term "cutoff," it states that processes identified (in the screening study) as being not relevant-thus neglible-do not need to be considered in the subsequent PEF study. As in ISO 14044 (2006), fixed criteria defining when a process is considered as relevant or not (e.g., contribution of less than $5 \%$ to the impact category) are not provided in the PEF/PEFCR Guides. As a result of the screening study during the PEFCR development, one may exclude certain impact categories in the PEFCR, if identified as not being relevant (European Commission 2014b), without knowing yet how relevance should be measured. Methodologically, excluding impact categories, however, means that elementary flows are cut off. Moreover, the PEF methodology provides numerous specifications, for example, on how to deal with fossil and biogenic carbon (C), land use change, $C$ storage, and so forth, or on quantitative minimum data quality requirements and data sources as well as regarding allocation by proposing a new "recycling formula." 
Regarding impact assessment and interpretation, the PEF methodology differs because it provides a default set of 14 impact assessment methods (further explained in the following section). Normalization is a recommended step and has to be tested within the PEF pilot phase. Therefore, European normalization factors are provided by the European Commission (European Commission 2014c). Considering only European emission data disregards the fact that most raw materials are produced outside of Europe. Furthermore, except for some aspects such as greenhouse gas emissions, global as well as regional emission data necessary to determine normalization factors are not yet available. Hence, the provided normalization factors are so far based on estimations, and normalized results should be interpreted with care, such as the significance of impact assessment categories for a specific product system (Heijungs et al. 2006; Benini et al. 2014). To calculate credits or burdens for the end of life (EoL), a specific formula to deal with multifunctionality in recycling situations is given (European Commission 2014b), which requires the collection of 18 factors regarding the EoL product system. Generic data should be used if specific data are not available. For bio-based plastic, in which so far generic processes are lacking, not all requested factors can be provided by the modeled system, and generic data from conventional plastic have to be considered. Thus, in this example, a distinction between the impacts of bio-based and conventional plastic in the EoL stage is not possible. Moreover, the PEF methodology allows weighting as an optional step (results provided as "additional environmental information") for business-to-business or business-toconsumers communication with comparisons and comparative assertions. This clearly contradicts ISO 14044 and ISO 14025 as well as the fact that a PEF study can be used as claim about the environmental superiority or equivalence of a product compared with another product (European Commission 2014b), whereas ISO states that LCIA shall not be the sole basis for interpretation in comparative assertions (ISO 14044 2006).

\section{Criteria-based evaluation of impact assessment methods}

In this section, the evaluation results for all 14 impact assessment methods are presented. Because of the complexity of the analysis, not all criteria can be discussed in detail. Key points that reflect the overall maturity of the method are highlighted.

Table 1 shows that stakeholder acceptance has been rated very well for most methods.

Environmental topics discussed in the public for years such as global warming (Barker 2007; IPCC 2007) have the advantage of being understood even by laymen, although underlying indicators might be complex. Stakeholder acceptance of methods for ionizing radiation, toxicity, water, and abiotic resource depletion is lacking as several sub criteria are evaluated with level 3. Because the methods for assessing abiotic resource depletion based on reserves instead of ultimate reserves (Guinée et al. 2001; Oers et al. 2002) and ionizing radiation (Frischknecht et al. 2000) have never been used in LCAs so far and therefore have never been tested, their stakeholder acceptance is rated as minor; however, for policy the abiotic depletion potential (ADP) method (Guinee et al. 2001) might be of interest as the economic resource availability is assessed. Because of its complexity and high uncertainties, the UseTOX method for assessing human and ecosystem toxicity (Rosenbaum et al. 2008; Rosenbaum et al. 2011) is limited in its comprehensibility and applicability for policy. Even though it becomes more reliable by addressing the uncertainties within a method, when these uncertainties are very high as is the case for USEtox, where the result varies by 1 or 2 orders of magnitude, policy cannot rely on the results. Furthermore, because USEtox has never been applied in a policy context before-contrary to, for example, the accumulated exceedance method for acidification and eutrophication, which has been used in mitigation strategies in Europe for yearsreal life experience using and interpreting this method is missing. The ecological scarcity method (Frischknecht et al. 2009) is easy to understand, but because of its severe flaws, such as modeling 
Table 1. Evaluation results of impact assessment methods shown for main criteria and subcriteria

\begin{tabular}{|c|c|c|c|c|}
\hline Impact Assessment Categories & Stakeholder Acceptance $^{a}$ & Documentation \& Review ${ }^{\mathbf{b}}$ & Environmental Relevance $^{c}$ & Applicability \\
\hline Climate change & 1 \# 1 \# 1 & 1 \# 1 \# 1 & 1 \# 1 \# 1 \# 1 \# 1 & $1 \# 1$ \\
\hline Ozone depletion & 1 \# 1 \# 1 & 1 \# 1 \# 1 & 1 \# 1 \# 1 \# 1 \# 1 & $1 \# 1$ \\
\hline Particulate matter & 1 \# 2 \# 2 & 2 \# 1.5 \# 3 & 2 \# 1 \# 1 \# 1 \# 1 & $2 \# 2$ \\
\hline lonizing radiation & 1 \# 3 \# 3 & 1 \# 1 \# 2 & $1 \# 1 \# 2 \# 2 \# 2$ & $3 \# 2$ \\
\hline Photochemical ozone creation & 1 \# 2 \# 2 & 2 \# 1 \# 3 & 1 \# 1 \# 1 \# 1 \# 1 & $2 \# 1$ \\
\hline Eutrophication, terrestrial & 1 \# 2 \# 1 & 2 \# 1 \# 3 & 3 \# 1 \# 1 \# 1 \# 1 & $2 \# 1$ \\
\hline Eutrophication, aquatic & 1 \# 2 \# 2 & 2 \# 1 \# 3 & 3 \# 1 \# 1 \# 1 \# 1 & $2 \# 1$ \\
\hline Acidification, aquatic & 1 \# 2 \# 1 & 2 \# 1 \# 3 & 3 \# 1 \# 1 \# 1 \# 1 & $2 \# 1$ \\
\hline Human toxicity, carcinogen & $3 \# 1 \# 2$ & 1 \# 1 \# 1 & 3 \# 2 \# 1 \# 1 \# 2 & $1 \# 2$ \\
\hline Human toxicity, noncarcinogen & $3 \# 1 \# 2$ & $1 \# 1 \# 1$ & $3 \# 2 \# 1 \# 1$ \# 2 & $1 \# 2$ \\
\hline Eco toxicity & 3 \# 1 \# 2 & 1 \# 1 \# 1 & 3 \# 2 \# 2 \# 2 \# 2 & $1 \# 2$ \\
\hline Land use & $1 \# 2 \# 2$ & 2 \# 1 \# 3 & $2 \# 3^{e}$ & $2 \# 2$ \\
\hline Water depletion & 1 \# 3 \# 3 & 1 \# 1 \# 3 & $2 \# 3 \# 3^{f}$ & $2 \# 3$ \\
\hline Abiotic resource depletion & 1 \# 3 \# 2 & $1 \# 1 \# 3$ & $2 \# 3^{g}$ & $1 \# 3$ \\
\hline
\end{tabular}

aSubcriteria: indicators and unit are easily understandable, an authorized body supports the method, usable results for policy are provided

bSubcriteria: method is documented, method is reviewed, model uncertainties are assessed

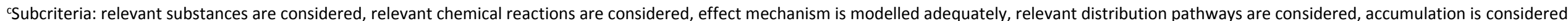

dSubcriteria: method is globally valid, inventory data are adequate

eSubcriteria: different land use types are considered, effect mechanism is modelled adequately

fSubcriteria: resource availability is considered, different water bodies are considered, regional differences are reflected

sSubcriteria: resource availability is considered, socio-economic factors are considered 
artefacts that lead to a higher water scarcity in Germany than in Australia (Finkbeiner 2014), it is not suitable for use in policy in its current form.

The documentation is evaluated as very well for most methods. However, some methods are using background models, which are not publicly accessible and are therefore ranked at level 2 . All methods besides the Riskpoll model for particulate matter (Rabl and Spadaro 2004) are published in scientific journals. Furthermore, only 5 of the 14 methods provide uncertainty assessments.

Many methods such as the World Meterological Organization method for ozone depletion (WMO 2010) or the IPCC (2007) for climate change perform very well regarding their environmental relevance. Because both methods are very mature, they could be used, not exclusively though, for a comparative assertion such as bio-based and conventional plastics. The ionizing radiation method (Frischknecht et al. 2000) only considers effect mechanism regarding nuclear power production and only within France. Thus, its reflection of the environmental relevance is not satisfying. The plastics example shows that ionizing radiation is predominantly related to electricity production. Because the method has not been tested sufficiently so far, that other pathways and related inventory data for, for example, fertilizer production (Scholten and Timmermans 1996), are considered adequately as well cannot be ensured. For the example chosen, this means that excluding this aspect could lead to an inequitable advantage for the bio-based material. The USEtox model (Rosenbaum et al. 2008) for assessing human toxicity and ecotoxicity only covers a small amount of the potentially toxic chemicals (although more than $\mathbf{3 0 0 0}$ characterization factors are included in the latest version [Rosenbaum et al. 2011] and cumulative toxic effects cannot be assessed so far [Finkbeiner et al. 2014]).

Thus, its environmental relevance is not satisfying. Some characterization factors such as those for metals are marked as interim; for them, proceeding with caution is advised (Rosenbaum et al. 2011). Hence, this method should be used with care in comparative LCA studies. The accumulated exceedance method (Seppälä et al. 2006) for acidification and eutrophication only provides few characterization factors (Seppälä et al. 2006; Finkbeiner 2014). Within the plastics example, the accumulated exceedance method (Seppälä et al. 2006) covers 7 elementary flows less for the acidification potential than the impact assessment method developed under the lead of the Center of Environmental Science of Leiden University (CML) (Guinee et al. 2001). For the products compared here, these neglected emissions only sum up to $2 \%$ of the overall impact, but for other product systems their contribution may be more significant, especially when metals are considered. The land use method (MilaiCanalsetal.2007) is the third evaluated as not being satisfactory. Soil organic matter only serves as a headline indicator for soil fertility and climate regulation; other aspects such as loss of biodiversity have to be considered by applying additional impact assessment methods (Mila i Canals et al. 2007; Brandao et al. 2011). Thus, this method should be applied with care within comparative studies as well, especially when the assessed systems differ significantly (such as for biobased vs conventional plastics). The ecological scarcity method (Frischknecht et al. 2009) used to assess water depletion does not adequately consider all environmental relevant factors for the resource freshwater, because it is only based on relative scarcity (Finkbeiner 2014). Because no regional inventory data are available in LCA databases so far, water footprint case studies are very time consuming and difficult to carry out, especially for complex industry products (Berger et al. 2012). For PEF studies, European weighted characterization factors are provided, which consider different water bodies but are not geographically explicit. Especially for the evaluation of water depletion, regional differences are of upmost importance (Pfister et al. 2009; Berger et al. 2014; Finkbeiner et al. 2014). Thus, applying results of average characterization factors cannot be used to support the decision making for a product system. This is shown in the example of bio-based plastics compared with conventional plastic, where regional differences are not considered and only the 
amount of water consumed is the deciding factor. Conventional plastic is produced from crude oil, which is extracted from countries all over the world. High amounts are obtained in Saudi Arabia (Central Intelligence Agency 2012), which is a water-scarce country. The bio-based plastic example cellulose acetate is made mainly from wood pulp (Sustainable Forestry Initiative 2014; Balser et al. 2015). Current trade statistics (United Nations Economic Commission for Europe 2013) show that low amounts of industrial round wood used for wood pulp are exported within Europe. Thus, the $30 \%$ cellulose acetate produced in Europe (Dammer et al. 2013) can be assumed to be manufactured from the wood of European trees. European countries have on average less water scarcity than most oilproducing countries outside of Europe. Thus, a regionalized impact assessment method should be recommended. The method for ADP (Guinee et al. 2001) is also not sufficient regarding its environmental performance, because it evaluates resources only from an economic point of view considering reserves. Neither physical availability nor proper socioeconomic factors addressing scarcity are considered. Furthermore, regarding the example, ADP indicator results for conventional plastic would probably be worse than for bio-based plastic because ADP only considers abiotic resources. So far, no impact assessment methods are available for evaluating biotic resource depletion (European Commission-Joint Research Centre-Institute for Environment and Sustainability 2011; Finkbeiner et al. 2014). Thus, a comparison of abiotic and biotic resource depletion is not possible.

The biggest challenge regarding the applicability of these methods is the availability of inventory data. Most of the methods including accumulated exceedance method (Seppälä et al. 2006) are not valid worldwide because only European background data are considered. When assessing silvicultural systems such as forestry for bio-based plastic, regional aspects might be of importance for the overall environmental profile. Acidifying substances, which are caused by transports, might be considered less or more critical when emitted, for example, in Canada instead of Europe. Because supply chains are spread out around the world, a uniform world model as used within RiskPoll (Rabl and Spadaro 2004) or USEtox (Rosenbaum et al. 2008) has clear advantages. Because eutrophication and acidification are assessed within LCA for many years, the inventory data can be assumed as more or less complete.

\section{RECOMMENDATIONS AND OUTLOOK}

In summary, half of the impact assessment methods evaluated here cannot be seen as adequate to be used solely for decision support such as comparative assertions. However, methods for global warming and ozone depletion are very good, as evaluated in all subcategories.

The idea of the PEF/OEF to harmonize existing life cycle-based methods is good, but although all methods reference ISO 14044 as their basis (except for the C footprint standards with limited focus of climate change) (Finkbeiner 2014), the PEF/ OEF methodology shows several differences and even contradiction, such as allowing for weighting of LCA results to single scores. Besides the fact that the new methodology may cause confusion amongst stakeholders and bears the risk of impeding a life cycle-based environmental analysis of products and services as such, the applicability (as well as the acceptance) of the method is not yet proven. Questions remain, for example, regarding the identification of suitable NACE/CPA codes, dealing with the ban of cutoffs, and impact assessment methods, especially for water depletion and land use. These questions and related challenges were discussed in this article and illustrated using a theoretical example comparing bio-based and conventional plastic. Identifying a suitable NACE/ CPA code is not a straightforward task, because more than one category would be needed to cover the product system adequately.

The evaluation of the PEF/OEF impact assessment methods and their application in the example showed that using the proposed methods for land use and water depletion is not recommended in 
general, but especially not for comparing different product systems. For water depletion, more commonly used and better tested methods are available (Pfister et al. 2009; Berger et al. 2014; Finkbeiner 2014). Other relatively new methods such as ionizing radiation (Frischknecht et al. 2000) or accumulated exceedance (Seppälä et al. 2006; Posch et al. 2008) should be tested regarding their applicability and necessity within the pilot phase. Applying USEtox (Rosenbaum et al. 2008) presents a challenge because of several issues mentioned within this paper. The pilot phase should be used to determine which product systems should use this method. The IPCC method (IPCC 2007) as well as the World Meterological Organization method (WMO 2010) can be applied without any difficulty. The results of this evaluation of impact assessment methods can be taken into account within the $\mathrm{PEF} / \mathrm{OEF}$ pilot phase, together with the original evaluation and classification of the European Commission (2011).

Furthermore, important environmental effects such as loss of biodiversity, which cannot be addressed adequately within LCA so far (Finkbeiner et al. 2014), might have a big influence on the result and should be considered qualitatively, maybe within the section Additional Environmental Information in the PEFCRs/OEFSRs.

Further challenges of the PEF methodology beyond the scope of this paper include the applicability of the data quality assessment scheme, the suitability of the provided allocation approach for recycling, and weighting or the identification of appropriate measures to communicate PEF/OEF results. Benchmarks and performance classes shall be defined during PEFCR development to enable comparisons between products, but for now it is not clear how they should be defined practically nor theoretically if a benchmark system is to be meaningful.

The European Commission promotes the use of PEF and OEF for measuring and communicating environmental life cycle performance of products and organizations. Thus, it provides opportunities to support decision-making processes at all levels, that is, industry and policy. However, for this, information obtained must be based on a solid methodology, and appropriate communication tools must be used, but both of these conditions are not yet ensured.

The ongoing pilot phase intends to test the PEF/OEF methodology, to deal with remaining questions, and to solve problems. This includes further clarifying the goal of PEF/OEF (PEFCR/OEFSR), testing normalization factors, reconsidering whether weighting is indeed an appropriate way for communicating LCA/PEF results, and adapting some of the predefined impact assessment methods (Finkbeiner 2014). The results of this paper are relevant for the pilot phase, because they highlight theoretical and practical challenges and propose possibilities to cope with them.

\section{REFERENCES}

Balser K, Hoppe L, Eicher T, Wandel M, Astheimer H-J., Steinmeier H. 2015. Cellulose esters. In: Ullmann's Encyclopedia of Industrial Chemistry. [cited 2015 April]. Available from: http://dx.doi.org/10.1002/14356007.a05_419

Barker T. 2007. Climate Change 2007: Climate Change 2007 : An Assessment of the Intergovernmental Panel on Climate Change Synthesis Report. Report available: https://www.ipcc.ch/pdf/assessmentreport/ar4/syr/ar4_syr_full_report.pdf

Benini L, Mancini L, Sala S, Manfredi S, Schau E, Pant R. 2014. Normalisation method and data for Environmental Footprints. Luxembourg: European Union. EUR 26842 EN.

Berger M, Ent R van der, Eisner S, Bach V, Finkbeiner M. 2014. Water accounting and vulnerability evaluation (WAVE): Considering atmospheric evaporation recycling and the risk of freshwater depletion in water footprinting. Environ Sci Technol 48:4521-4528.

Berger M, Warsen J, Krinke S, Bach V, Finkbeiner M. 2012. Water footprint of European cars: Potential environmental impacts of water consumption along automobile life cycles. Environ Sci Technol 46:4091-4099.

Brandao M, Canals LMI, Clift R. 2011. Soil organic carbon changes in the cultivation of energy crops: Implications for GHG balances and soil quality for use in LCA. Biomass Bioenergy 35:2323-2336. 
Central Intelligence Agency. 2012. The World Factbook-COUNTRY COMPARISON_CRUDE OIL_PRODUCTION. Available from: https://www. cia.gov/library/publications/the-world-factbook/rankorder/2241rank.html

Dammer L, Carus M, Raschka A, Scholz L. 2013. Market Developments of and Opportunities for biobased products and chemicals. Report written for: Agentschap NL, The Netherlands.

European Commission. 2014a. Product Environmental Footprint News. Prod. Environ. Footpr. News [Internet]. [cited 2015 April]. Available from: http://ec. europa.eu/environment/eussd/smgp/product_footprint.htm

European Commission. 2014b. Guidance for the implementation of the EU Product environmental Footprint (PEF) during the Environmental Footprint (EF) pilot phase-version 3.4.:1-34.

European Commission. 2014c. Guidance for the implementation of the EU Product environmental Footprint (PEF) during the Environmental Footprint (EF) pilot phase-version 3.3.:1-34.

European Commission-Joint Research Centre-Institute for Environment and Sustainability. 2011. International Reference Life Cycle Data System (ILCD) Handbook: Recommendations for Life Cycle Impact Assessment in the European context.

European Union. 2013a. Commission Recommendation of 9 April 2013 on the use of common methods to measure and communicate the life cycle environmental performance of products and organisations. Official Journal of the European Union L12456.

European Commission. 2013b. Building the Single Market for Green Products. Facilitating better information on the environmental performance of products and organisations. Communication from the commission to the european parliament and the council (COM(2013) 196 final., Brussels.

Finkbeiner M, Ackermann R, Bach V, Berger M, Brankatschk G, Chang Y-J., Grinberg M, Lehmann A, Martınez-Blanco J, Minkov N, Neugebauer S, Scheumann R, Schneider L, Wolf K. 2014. Challenges in Life Cycle Assessment: An Overview of Current Gaps and Research Needs. In: Background and Future Prospects in Life cycle Assessment. Berlin (DE): Springer. p 207-258.

Finkbeiner M. 2014. Product environmental footprint-breakthrough or breakdown for policy implementation of life cycle assessment? Int J Life Cycle Assess 19:266-271.

Franze J, Ciroth A. 2011. A comparison of cut roses from Ecuador and the Netherlands. Int J Life Cycle Assess 16(4):366-379.

Frischknecht R, Braunschweig A, Hofstetter P, Suter P. 2000. Human health damages due to ionising radiation in life cycle impact assessment. Environ Impact Assess Rev 20:159-189.

Frischknecht R, Steiner R, Jungbluth N. 2009. The Ecological Scarcity Method- Eco-Factors 2006: A method for impact assessment in LCA (Methode der ökologischen Knappheit-Ökofaktoren 2006, Methode für die Wirkungsabschätzung in Ökobilanzen). Bern (DE): Federal Office for the Environment. $188 \mathrm{p}$.

Galatola M, Pant R. 2014. Reply to the editorial "Product environmental footprint-breakthrough or breakdown for policy implementation of life cycle assessment?" written by Prof. Finkbeiner (Int J Life Cycle Assess 19(2): 266-271). Int J Life Cycle Assess 19:1356-1360.

Guinee JB, Gorree M, Heijungs R, Huppes G, Kleijn R, Koning A de, Oers L van, Sleeswijk AW, Suh S, Haes HAU de, et al. 2001. Handbook on life cycle assessment. Operational guide to the ISO standards. I: LCA in perspective. Ila: Guide. IIb: Operational annex. III: Scientific background. Available from: http://cml.leiden.edu/research/industrialecology/researchprojects/finished/ new-dutch-lca-guide.html

Heijungs R, Guinee J, Kleijn R, Rovers V. 2006. Bias in normalization: Causes, consequences, detection and remedies. Int J Life Cycle Assess 12:211-216.

[IPCC] Intergovernmental Panel on Climate Change. 2007. Climate Change 2007: Synthesis Report. Contribution of Working Groups I, II and III to the Fourth Assessment Report of the Intergovernmental Panel on Climate Change [Core Writing Team, Pachauri, R.K and Reisinger, A. (eds.)]. IPCC, Geneva, Switzerland, 104 pp.

ISO 14025. 2006. International Standard-Environmental labels and declarations-Type III environmental declarationsPrinciples and procedures.

ISO 14044. 2006. International Standard-Environmental management-Life cycle assessment-Requirements and guidelines.

Martınez-Blanco J, Lehmann A, Munoz P, Anton A, Traverso M, Rieradevall J, Finkbeiner M. 2014. Application challenges for the social LCA of fertilizers within life cycle sustainability assessment. J Clean Prod 69:34-48.

Mila i Canals L, Bauer C, Depestele J, Dubreuil A, Knuchel RF, Gaillard G, Michelsen O, Müller-Wenk R, Rydgren B. 2007. Key elements in a framework for land use impact assessment within LCA. Int J Life Cycle Assess 12:5-15.

Oers L van, Koning A de, Guinee JB, Huppes G. 2002. Abiotic resource depletion in LCA Improving characterisation factors for abiotic resource depletion as recommended in the Dutch LCA Handbook. http://media.leidenuniv.nl/legacy/ report\%20abiotic\%20resource\%20depletion.pdf

Orgalime, ACEA, ANEC. 2013. Environmental footprint methodology: Not for US state consumers and manufactures. Joint Press Information. Available from: http://www.orgalime.org/sites/default/files/JPI_PEF_Methodology_Mar13.pdf 
Pfister S, Koehler A, Hellweg S. 2009. Assessing the environmental impacts of freshwater consumption in LCA. Environ Sci Technol 43:4098-4104.

Posch M, Seppälä J, Hettelingh J-P, Johansson M, Margni M, Jolliet O. 2008. The role of atmospheric dispersion models and ecosystem sensitivity in the determination of characterisation factors for acidifying and eutrophying emissions in LCIA. Int J Life Cycle Assess 13:477-486.

Rabl A, Spadaro JV. 2004. RiskPoll: A model for estimating public health and environmental impacts of air pollution and pollution. Software version 1.051. Available from: http://www.arirabl.com

Reimann K, Finkbeiner M, Horvath A, Matsuno Y, Preto U, Pennington D, Pant R. 2010. Evaluation of environmental life cycle approaches for policy and decision making support in micro and macro level applications. Available from: DOI: $10.2788 / 32275$

Rosenbaum RK, Bachmann TM, Jolliet O, Juraske R, Koehler A, Hauschild MZ. 2008. USEtox: The UNEP-SETAC toxicity model: Recommended characterisation factors for human toxicity and freshwater ecotoxicity in life cycle impact assessment. Int J Life Cycle Assess 13:532-546.

Rosenbaum RK, Huijbregts MAJ, Henderson AD, Margni M, McKone TE, Meent D, Hauschild MZ, Shaked S, Li DS, Gold LS, Jolliet O. 2011. USEtox human exposure and toxicity factors for comparative assessment of toxic emissions in life cycle analysis: sensitivity to key chemical properties. Int J Life Cycle Assess 16:710-727.

Scholten LC, Timmermans CWM. 1996. Natural radioactivity in phosphate fertilizers. Nutr Cycl Agroecosystems 43:103-107.

Seppälä J, Posch M, Johansson M, Hettelingh J-P. 2006. Country-dependent characterisation factors for acidification and terrestrial eutrophication based on accumulated exceedance as an impact category indicator. Int J Life Cycle Assess 11:403-416.

Sustainable Forestry Initiative. 2014. Cellulose Acetate Polymer. http://www. acetateweb.com/wpcontent/uploads/2014/06/Att.10_GAMA-article-prf1.pdf

United Nations Economic Commission for Europe. 2013. Forest Products Annual Market Review 2012-2013. ECE/TIM/SP/33. Available from: http://www. unece.org/fileadmin/DAM/timber/publications/FPAMR2013.pdf

[WMO] World Meteorological Organization. 2010. Scientific assessment of ozone depletion: 2010 Global Ozone Research and Monitoring Project-Report No. 52. Geneva (CH): WMO. 516 p. 